\title{
Percutaneous Coronary Intervention Through the Impella System Sheath. A New Strategy to Limit Number of Access Sites in High Risk Patients
}

Taha Ahmed, Hafeez ul Hassan Virk and E Dean Nukta*

Department of Cardiology, Fairview Hospital, Cleveland Clinic, USA

*Corresponding author: E Dean Nukta, Department of Cardiology, Fairview Hospital, Cleveland Clinic, USA

\section{History}

A 64-year-old male who presented with retrosternal chest pain for 1 day.

\section{PMH/PSH}
a. HTN
b. DM II (last HbA1C 11.9)
c. Bowel obstruction $\mathrm{s} / \mathrm{p}$ hemi-colectomy
d. Tobacco abuse
e. Recent mesh repair of an incarcerated ventral hernia at an outside facility
f. SNF resident.

\section{VS}

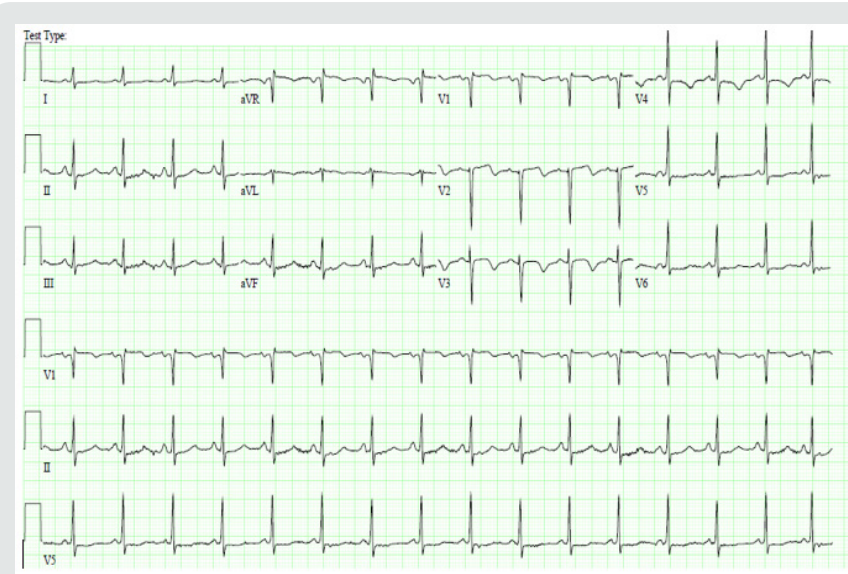

Figure 1.
a. HR: $114 \mathrm{bpm}$
b. BP: $149 / 75 \mathrm{~mm}$ of $\mathrm{Hg}$

\author{
c. $\quad$ RR: $32 / \mathrm{min}$ \\ d. Temp: $38.3 \mathrm{C}$ (Figure 1)
}

Electrocardiogram

TWI in leads V3-V5.

\section{Troponin $\mathrm{T}$}

$4 \mathrm{ng} / \mathrm{dl}=>12 \mathrm{ng} / \mathrm{dl}$.

\section{Echocardiogram}

Mildly decreased left ventricular systolic function with ejection fraction of $45 \%$ with no significant valvular or pericardial abnormalities.

\section{Diagnostic Left heart catheterization}
a. $\quad 90 \%$ stenosis of proximal left anterior descending (LAD) artery
b. $\quad 80 \%$ stenosis of mid left circumflex (LCx) artery
c. chronic total occlusion of right coronary artery (RCA)
d. SYNTAX score of 19 (Figure 2)
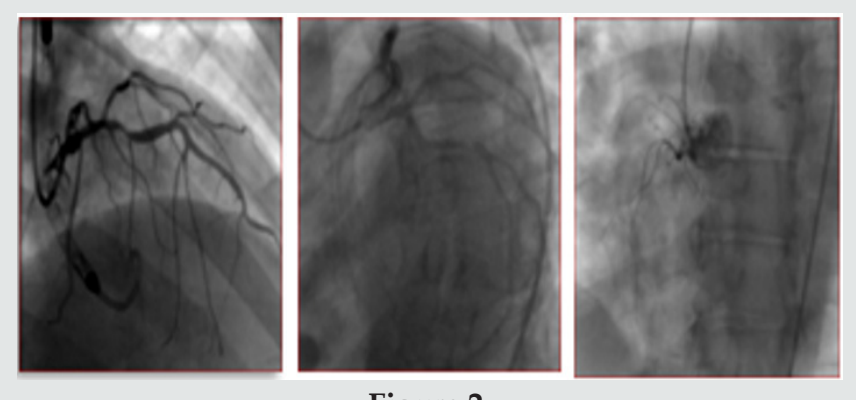

Figure 2. 


\section{Decision Making}

a. Patient was referred for CABG surgery and CTS consulted.

b. After detailed discussion with the patient, patient refused to undergo another surgery based on recent unpleasant surgical experience.

c. An interventional approach was contemplated, after discussion with the heart team.

d. High risk PCI with Impella support and angioplasty through the Impella system sheath via femoral approach was planned.

\section{Technique}

a. A $14 \mathrm{Fr}$ access arterial sheath was introduced in the right femoral artery percutaneously. The Impella CP system was prepared and flushed.

b. Over an exchange wire, the device was advanced under fluoroscopy across the aortic valve, wire was removed.

c. The device was connected to the driver unit and the device position was confirmed on fluoroscopy. Impella system was started and hemodynamic support was established (Figure 3).

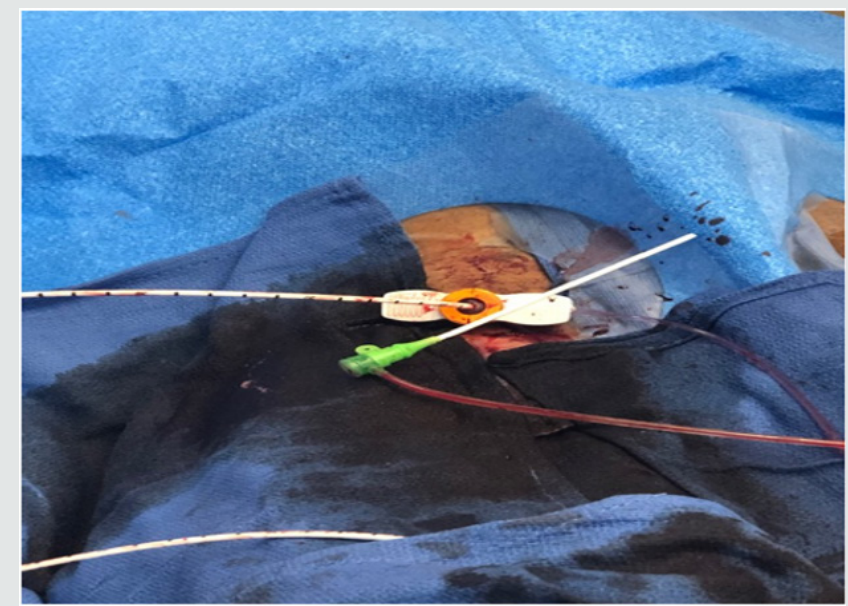

Figure 3.

d. A 6Fr sheath was introduced into the Impella access sheath next to the $9 \mathrm{Fr}$ Impella catheter and a guiding catheter was advanced under fluoroscopy and the vessel was engaged.

e. Angioplasty with placement of drug eluting stent to proximal LAD stenosis and mid LCx was performed with $0 \%$ residual stenosis.

f. The sheath was removed and hemostasis was established using perclose closure device.

g. There was no bleeding at the end of the procedure. The patient was returned to the recovery room in a stable condition.

h. There was no access site complication in 6 weeks follow up visit (Figure 4).
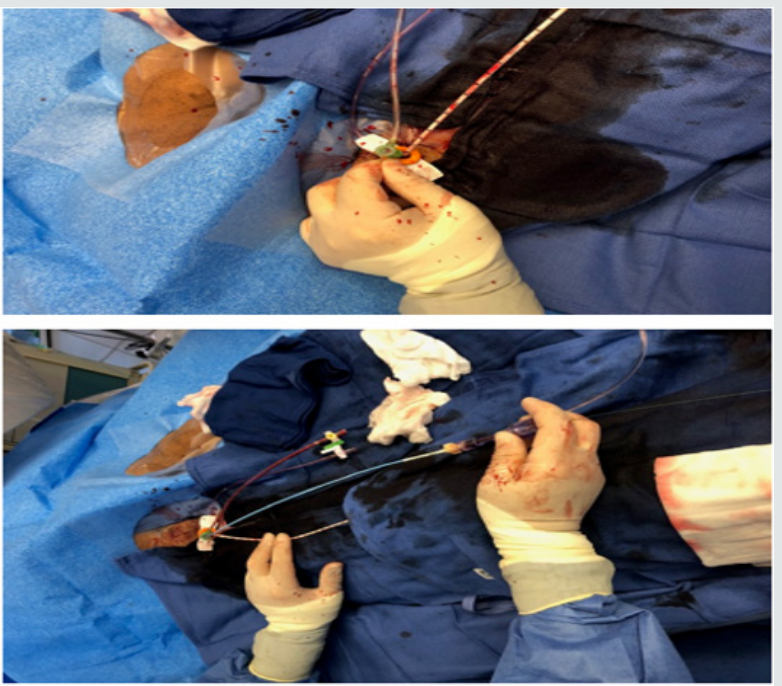

Figure 4 .

\section{Conclusion}

a. We present a case of a diabetic, hypertensive male with severe complex coronary artery disease who underwent high risk percutaneous coronary intervention (PCI) via the Impella system sheath with a favorable outcome (Figure 5).

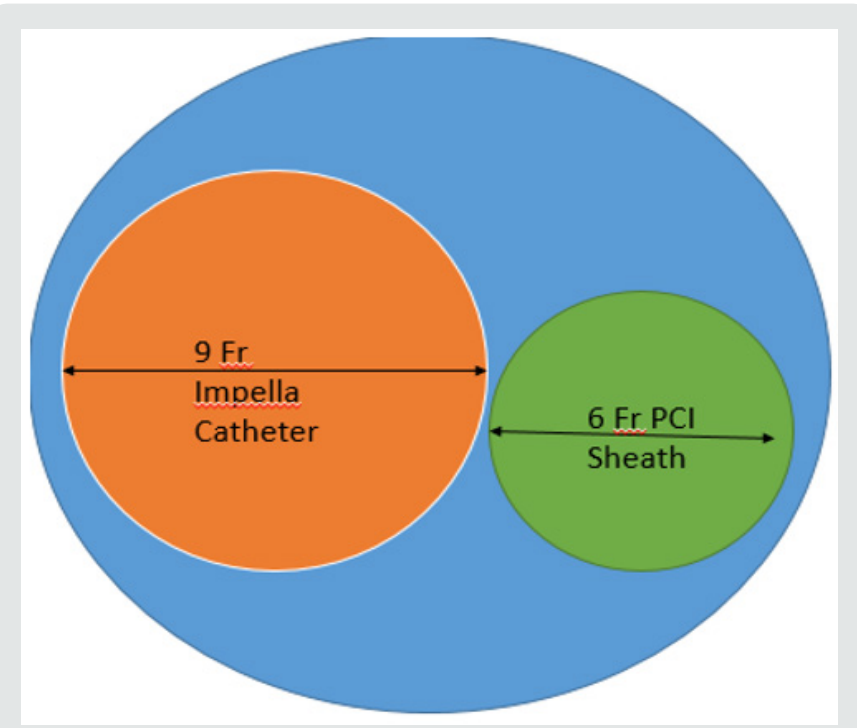

Figure 5: 14 Fr Impella Catheter Sheath

b. It is one of the first known cases of this innovative nature that brings into consideration the importance of dual vascular access via the Impella system sheath.

c. The patient tolerated the procedure well with no complications at the follow up visit.

d. The case was discussed with the heart team, which has become the standard for high risk and complex decisions.

e. In high risk coronary artery disease patients, PCI can be performed safely via the Impella system sheath therefore avoiding unnecessary vascular access and associated complications. 
This work is licensed under Creative Commons Attribution 4.0 License

To Submit Your Article Click Here: Submit Article

DOI: 10.32474/ACR.2019.02.000140

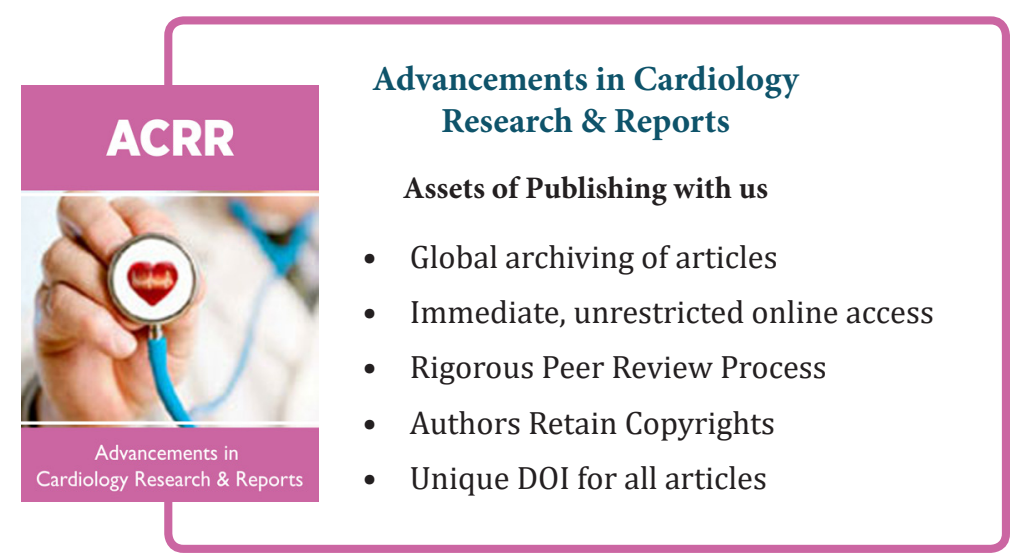

